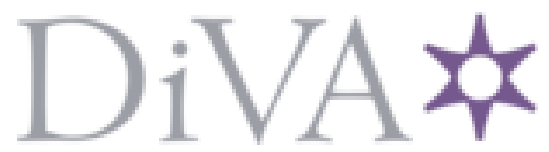

http://www.diva-portal.org

\title{
Postprint
}

This is the accepted version of a paper published in Early Child Development and Care. This paper has been peer-reviewed but does not include the final publisher proof-corrections or journal pagination.

Citation for the original published paper (version of record):

Bourbour, M., Masoumi, D. (2016)

Practise what you preach: the Interactive Whiteboard in preschool mathematics education.

Early Child Development and Care, 186(7)

http://dx.doi.org/10.1080/03004430.2016.1192617

Access to the published version may require subscription.

N.B. When citing this work, cite the original published paper.

Permanent link to this version:

http://urn.kb.se/resolve?urn=urn:nbn:se:hig:diva-22038 


\section{Practise what you preach: The interactive whiteboard in preschool mathematics education}

Maryam Bourbour

Davoud Masoumi *

Faculty of Education and Business Studies, University of Gävle, SWEDEN

The interactive whiteboard (IWB) is now a common technological artefact in Swedish preschools and schools. This study examines preschool teachers' thinking behind the embedding of IWB in the early years' mathematics classroom and how preschool teachers structure their mathematical activities when using IWB. Two complementary empirical studies, i.e. interviews and video observations, were conducted with four preschool teachers. The findings demonstrate that (just) having a positive attitude to technological artefacts like IWB is less likely to enrich the learning environment and lead to pedagogical change. This suggests that teachers' IWB use is mostly informed by their pedagogical knowledge.

KEYWORDS: Preschool teacher; mathematics education; Interactive Whiteboard (IWB); children; digital technology

Correspondence should be sent to Maryam Bourbour, Department of Education, University of Gävle, SE-801 76 Gävle, Sweden. Email: mambor@hig.se

\section{Introduction}

By providing young children with stimulating learning environments in which to play, learn and develop, early childhood education lays the foundation for lifelong learning. The Swedish 
preschool curriculum was introduced in 1998 and underlines the importance of the preschool as a first and key step in children's development. According to the Swedish preschool curriculum (The Swedish National Agency for Education, 2011), children should become acquainted with the curriculum and develop their understanding of specified knowledge domains.

The development of young children's mathematical concepts and skills is regarded as important in both preschools and schools (Björklund, 2012; Doverborg \& Emanuelsson, 2006). By helping young children to learn logical ways of working and communicating, mathematics education can provide them with an understanding and appreciation of spatial and quantitative reasoning, deduction and induction and analogical reasoning (Clements, Sarama, \& DiBiase, 2003; English, 2004).

The Swedish curriculum for early childhood education (2011) highlights the preschool teacher's role in developing children's abilities to express, explore and use mathematical concepts and understand the relationships between them. Preschool teachers thus have an important role to play in supporting and developing young children's mathematical learning by creating stimulating learning environments and providing opportunities to embed mathematics in the children's everyday lives (Björklund, 2012; Doverborg, 2006). Pramling Samuelsson and Sheridan (2007) argue that mathematical and critical thinking should be integrated into children's everyday lives. Mathematics thus becomes a critical artefact in children's reasoning processes in terms of understanding magnitude, sharing and comparing quantities, estimating the surrounding world and communicating these with other people (Björklund, 2010).

The rapid development of digital technologies has created opportunities for learning and development and placed new demands on individuals' knowledge and skills (Säljö, 2005). Research on digital technologies in learning environments has shifted the focus from the question of whether digital technologies can promote young children's learning to how these technologies can be embedded in learning environments (see Kervin, Verenikina, Wrona, \& Jones, 2010; Maher, 2011; Mercer, Hennessy, \& Warwick, 2010; Plowman \& Stephen, 2003). Similarly, the necessity of using digital technologies is highlighted in the revised Swedish preschool curriculum.

In order to develop a constructive educative environment in preschools, increasing efforts have been made to integrate digital technologies into early childhood education. A large number of Swedish preschools and schools have invested significantly in digital technologies 
and enhancing teachers' Information and Communication Technology (ICT) literacy and skills (Kjällander, 2014). Some technological artefacts, such as the interactive whiteboard (IWB) and tablets, appear to have attracted more interest than other digital technologies, e.g. beamers, personal computers etc. (Maher, 2011). In countries like the UK, IWB has become a common teaching artefact in both schools and preschools (Armstrong et al., 2005).

IWB is a large touch-sensitive screen connected to a computer and a digital projector. Using a digital pen, you can write and draw directly on the screen. IWB applications make it possible to prepare learning environments for different activities. The screen has a number of features, such as minimising, enlarging and moving pictures and figurines to create and support learning activities. By offering three-dimensional visualising and multimedia resources, such as text, images, animations, video, audio, graphics, online/offline applications and websites, IWB provides new opportunities to promote children's learning (Kervin et al., 2010).

Research findings (Glaubke, 2007; McCarrick \& Li, 2007; Penuel, Pasnik, Bates, Townsend, \& Gallagher, 2009; Sarama, 2004; A. Smith, Gentry, \& Blake, 2012) indicate that digital technologies can motivate young children, capture their attention and help teachers to enrich young children's learning environments. Similarly, a number of studies specifically underline that IWB can motivate young children to learn and enhance their cognitive skills by providing different learning opportunities and modelling abstract ideas and concepts in an authentic way (Goodwin, 2008; Watson \& De Geest, 2005). Another report by The Swedish National Agency for Education (2013) shows that IWB can enhance the learning and teaching processes in different educational contexts. Interestingly, many of these studies argue that the effectiveness of IWB in educational settings mostly depends on the ways in which this technological artefact is embedded (see Divaharan \& Koh, 2010).

Preschool teachers play a central role in designing and structuring children's learning environments. Helping young children to develop their mathematical abilities by problematising the surrounding world and challenging their mathematical thinking using different artefacts is an important part of this work (Björklund, 2010). Preschool teachers' pedagogical values, teaching and learning preferences can determine how they enact mathematical learning in the preschool and how they embed digital technologies in their teaching and learning practices (A. Smith et al., 2012).

Despite major investments in digital technologies, and the increasing availability of these technologies in Swedish preschools, the use of such tools varies (SOU, 2014:13). It would seem that a number of preschool teachers (in Sweden) do not make full use of the 
opportunities that digital technologies offer in early childhood education (see Masoumi, 2015).

The ways in which IWB can be used have been empirically investigated in a number of educational settings, particularly with regard to children's language learning and literacy (see Kervin et al., 2010; Maher, 2011; Mercer et al., 2010; Muir, Callingham, \& Beswick, 2016). However, very few studies document the ways in which IWB can be embedded in Swedish preschool practices. Further, very few studies include teachers' reasoning about and use of digital technologies in preschool practices. It is important to add that preschools in Sweden are based on the educare (education and care) model, which has been internationally acclaimed and highlighted as a role model. Accordingly, this study aims to contribute to the current knowledge about preschool teachers' reasoning, i.e. the thinking behind the embedding of IWB in the early years' mathematics classroom and the ways in which preschool teachers structure their mathematical activities when using IWB.

\section{Method}

The study consists of two complementary empirical cases, carried out with four preschool teachers in two preschools in Gothenburg, the second largest metropolitan area in Sweden. It should be mentioned that the preschools were recommended for the study by the regional administration due to the frequent use of IWB in their educational practices.

The first case study makes use of an interview study with semi-structured questions in order to investigate preschool teachers' reasoning about the use of IWB in early years' mathematics. Semi-structured interviews conducted with four preschool teachers enabled the teachers to elaborate on and exemplify their own reasoning about, associations with, experiences of and initiatives (Creswell, 2012) taken when using IWB in the early years' mathematics classroom. The interviews were conducted and audio-recorded in the spring of 2012. Each interview lasted for one and a half to two hours. The interviews resulted in 6 hours and twenty minutes of recorded material. All the interviews were transcribed verbatim. The transcribed interviews were then examined independently by the authors to discern the teachers' expressed meanings and approaches. In order to deepen the understanding of the teachers' reasoning about teaching mathematics with IWB, the interviews were analysed using content analysis as described in Creswell (2012).

The second study expands on the previous one by examining how the mathematical activities are structured using IWB. The empirical data for the study consists of observations of three 
preschool teachers in one preschool (three out of the four interviewed teachers ${ }^{1}$ ). The studied preschool is located in an immigrant area and around 90 per cent of the children attending the preschool have an immigrant background. As a consequence, all the participating children in this study are children of immigrants. This also means that these children are in the process of learning a new language, i.e. Swedish. All the participating children are between three and six years of age.

The written consent of both teachers and parents was obtained before the empirical study began. The teachers and parents were told about the research goals and how the study would be conducted at a parents' meeting, where opportunities to ask questions or raise concerns were provided. Information was also made available in writing.

The researchers visited the preschools on six separate occasions, i.e. twice for each of the studied preschool teachers and their respective groups. The visits varied in length from two hours to a whole day; the aim being to work with and become acquainted with the children in order to reduce the effect of the presence of the researchers and the video camera. After the focused activities led by the preschool teachers, the children were allowed to play freely with the IWB. Following the aim of the study, the teachers' use of IWB was video-recorded, which amounted to around 25 minutes for each observed session.

The analytical method employed in this part of the study is Interaction Analysis (IA), as defined by Shadish, Cook, and Campbell (2002). The analysis focuses on the preschool teachers' practices, such as talk, nonverbal interactions and how they structure the mathematical activities using IWB.

\section{Research findings and discussions}

The main themes to emerge from the collected data are reflected in two main categories: 1) preschool teachers' reasoning, i.e. the thinking behind the embedding of IWB in the early years' mathematics classroom and 2) the ways in which preschool teachers structure their mathematical activities when using IWB.

\section{Preschool teachers' reasoning about young children's mathematics education using IWB}

The interviewed preschool teachers highlight the importance and significance of embedding technological artefacts such as IWB in Swedish preschools in order to create meaningful

\footnotetext{
${ }^{1}$ One of the interviewed preschool teachers did not feel able to participate in the second part of the study.
} 
learning environments and facilitate young children's mathematical education. They also indicate that mathematics is usually seen as a very important part of the preschool's everyday activities. In the following excerpt, David (one of the preschool teachers who was interviewed) highlights the importance of IWB for creating meaningful learning environments for children.

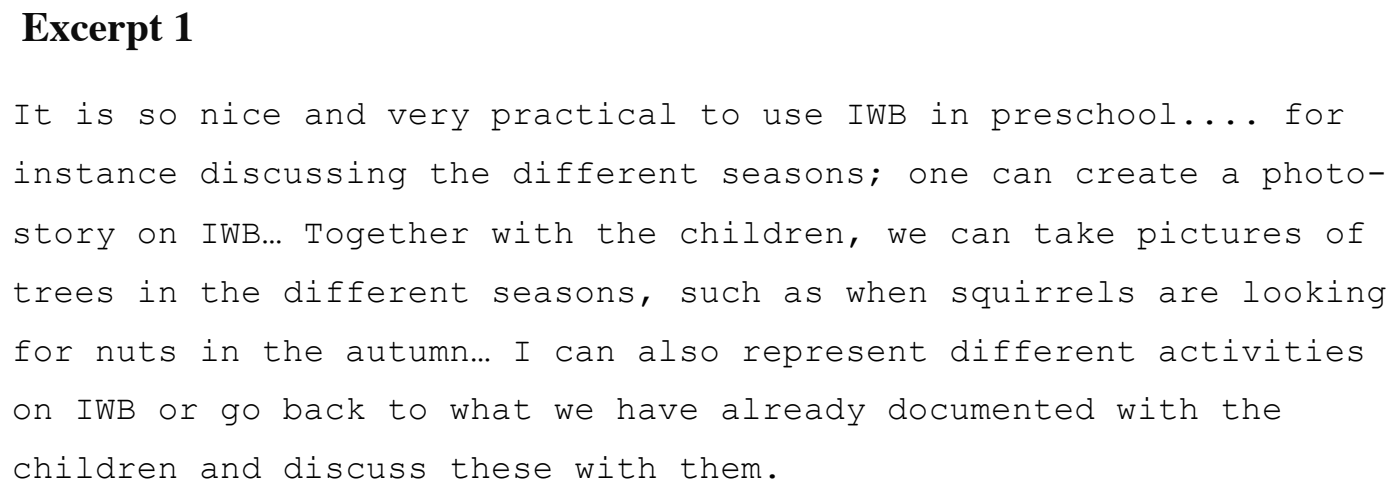

As reflected in excerpt 1, David argues that IWB offers children a variety of opportunities to develop mathematical concepts and skills. He explains how he uses IWB to introduce and describe the different seasons by animating and manipulating pictures and contexts and adding text and audio. According to this teacher, the features on the IWB provide opportunities to discuss different topics and work with the children. Mats, another preschool teacher, praises the various aspects of IWB, such as its visual nature and the large touchsensitive board, for enhancing young children's learning.

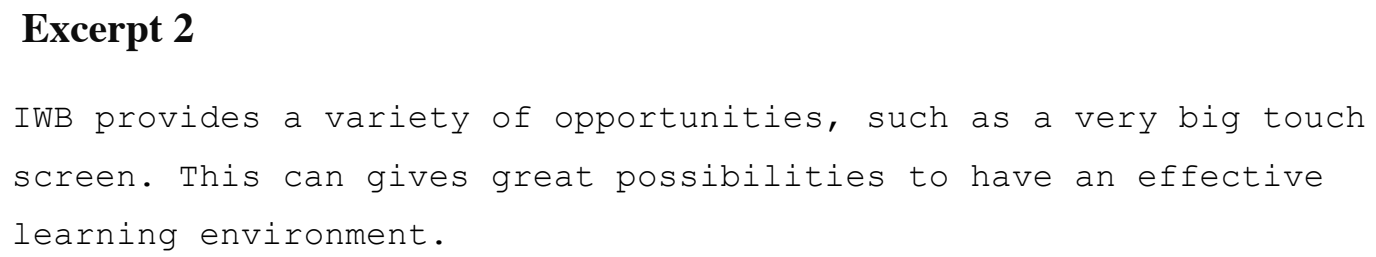

Involving children in problem-solving situations is another important rationale for embedding IWB in preschool educational practices. In the following excerpt, Camila argues that using IWB in problem-solving activities can increase young children's involvement in mathematical learning:

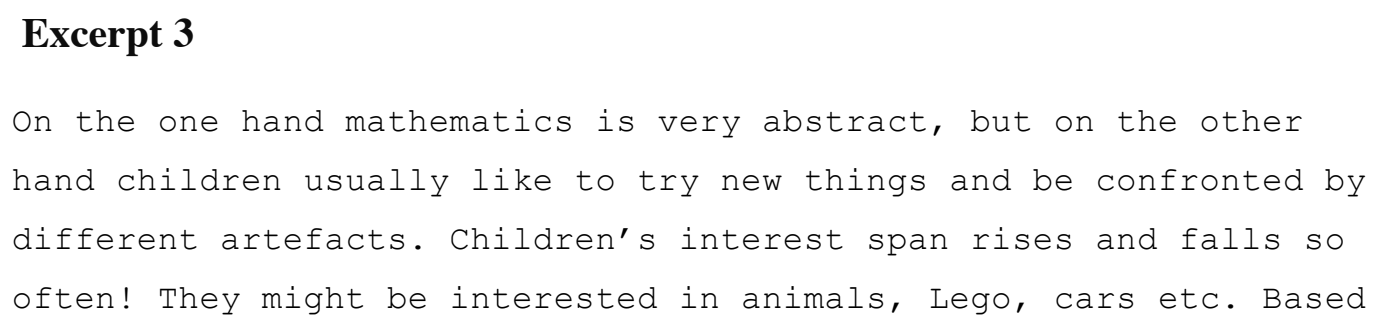




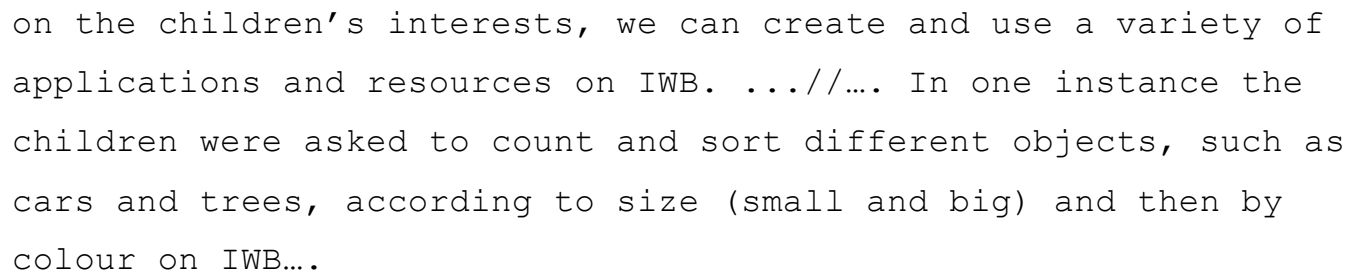

As reflected in excerpt 3, IWB appears to provide preschool teachers with a variety of opportunities and multimedia possibilities to engage and sustain children's interest. According to the interviewed preschool teachers, using IWB with multimedia features and functionalities to visualise and animate mathematical problems and concepts can engage children's in the learning process. Another preschool teacher, Mona, talks about making a maths game for those children who are good at the subject:

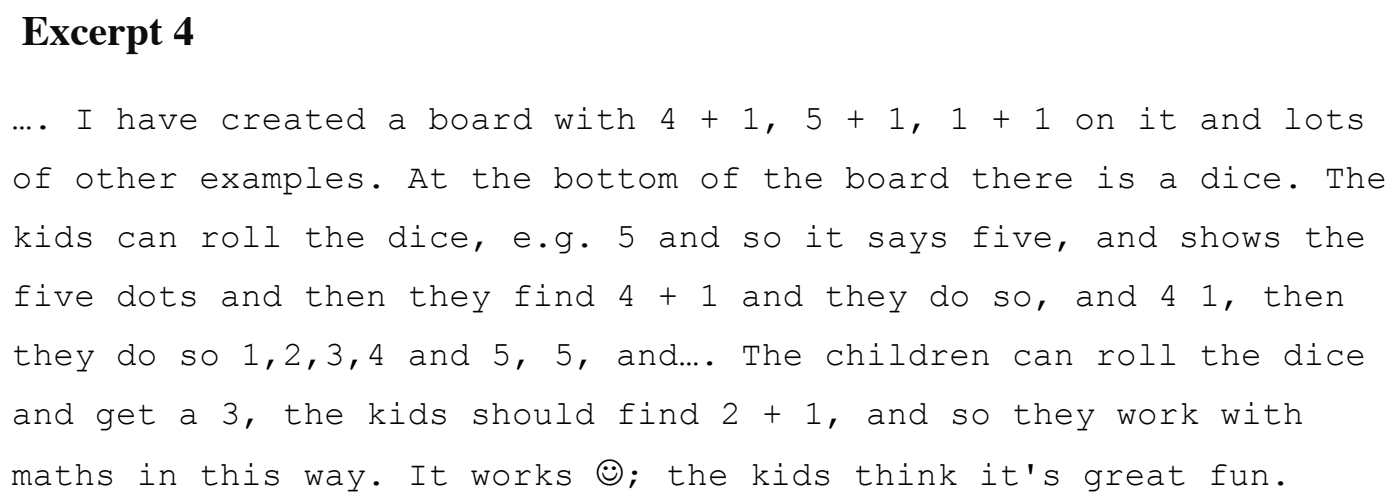

According to the interviewed preschool teachers, IWB is seen as an educational artefact that enables them to take children's different ways of learning mathematics into account. Moreover, they argue that using IWB can actively engage young children in the learning process. They give examples of ways in which children can be engaged in learning situations, but do not fully explain how the meaning of the mathematical phenomena is mediated through the technology.

The interviews also reveal examples of mathematics education practices facilitated by IWB. For example, David describes how he made use of IWB to motivate children to work with each other by illustrating animals (wild and farm animals) known to them. He asks the children to classify animals based on their unique characteristics, e.g. length, weight, colour, type of food and thinks that group discussions, the negotiation of meaning and mutual support among the children could be fostered by the use of IWB.

\section{Structuring mathematical activities with IWB}

In except 1, David explains how he structures his mathematics lessons with IWB. He illustrates his teaching material using familiar characters, such as Alfons, Pippi Longstocking, 
princes and princesses. He also structures his learning materials using characters ${ }^{2}$ from the children's storybook "Three little pigs" (see Figure 1).

At the beginning of the activity, David introduces the application to a group of young children. The application is for storytelling, in which figures and backgrounds can be animated and modified.

\section{Figure 1. Role play}

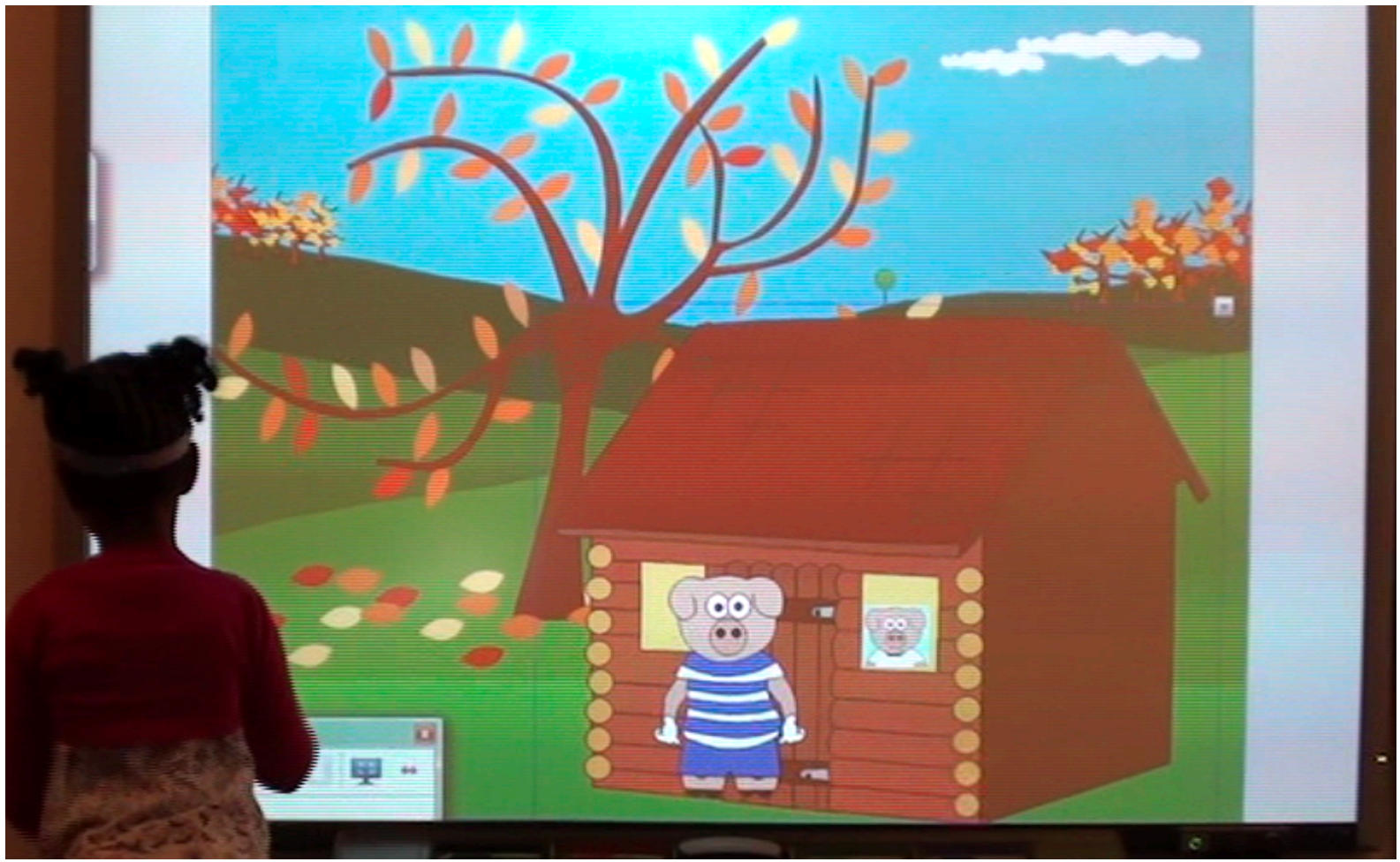

In this case, the teacher had already chosen a storyline that the children were familiar with.

\section{Excerpt 5}

1. The teacher and the children are sitting on a bench and discussing the roles they would like to play. Who wants to be the mother pig, the first little pig, the second little pig, the third little pig and the wolf?

2. Yunis: I want be the mother pig.

3. Narin: I want to be the first little pig,

4. Atefeh wants to be the second little pig,

5. Azim wants to be third little pig,

\footnotetext{
${ }^{2}$ Popular characters in Swedish children's literature.
} 


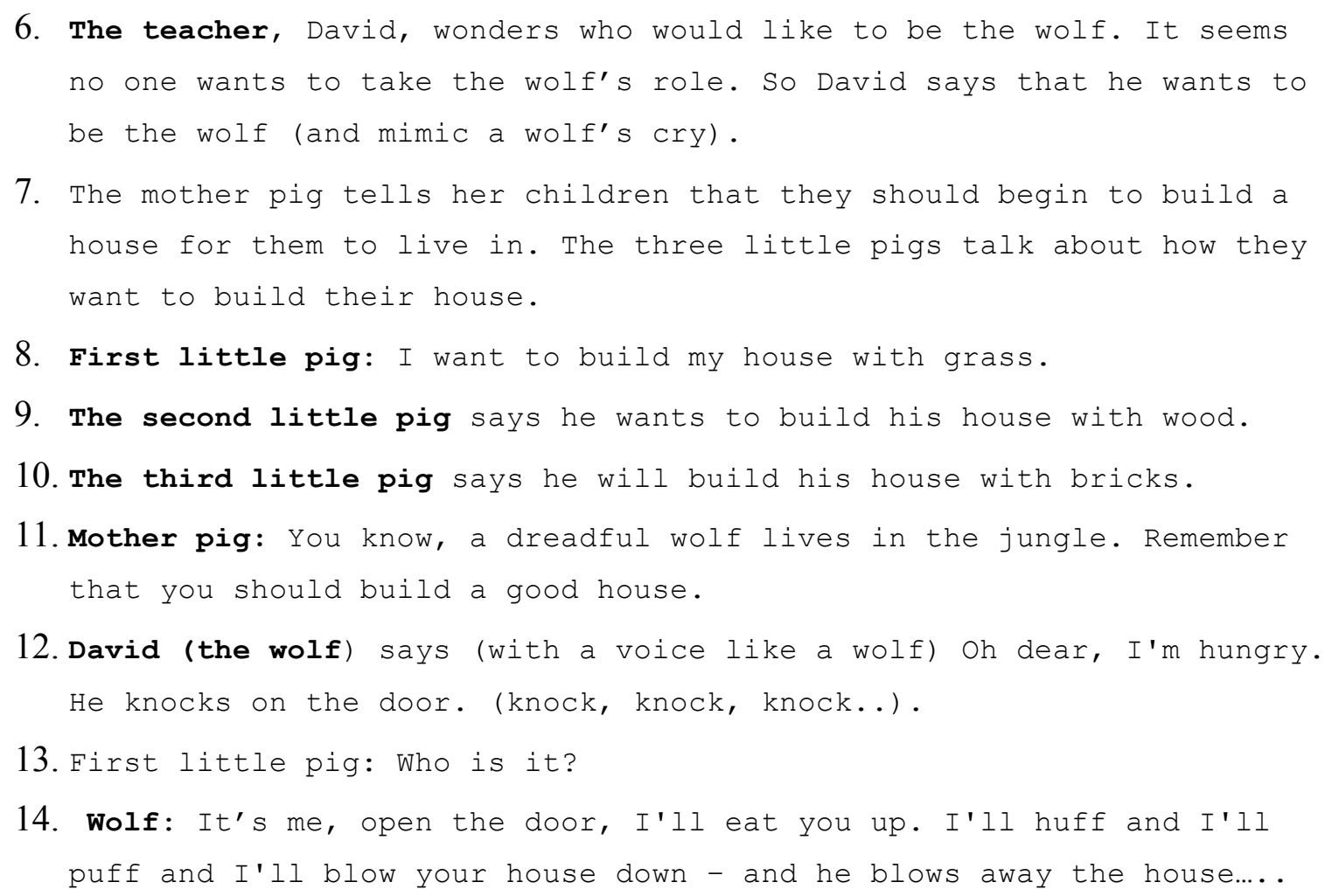

By playing different roles and engaging the children in the activity, the teacher uses the multisensory resources - animation, voice, music - of the IWB to involve the children in the learning process. Using familiar stories, the teacher helps the children to develop their understanding of numbers and ordinal numbers. Interestingly, mathematical concepts such as identifying positions, i.e. above, below, beside, inside, outside, underneath and over, and learning to count, are embedded in the story. The children are also engaged and excited by what they are able to do during the activity.

In another activity David uses IWB to help young children solve problems. As indicated in the following excerpt, David introduces different mathematical concepts, such as size, comparison, direction and order using a resource with cartoon-like images that he has made himself.

\section{Figure 2. Ordering and comparing objects}




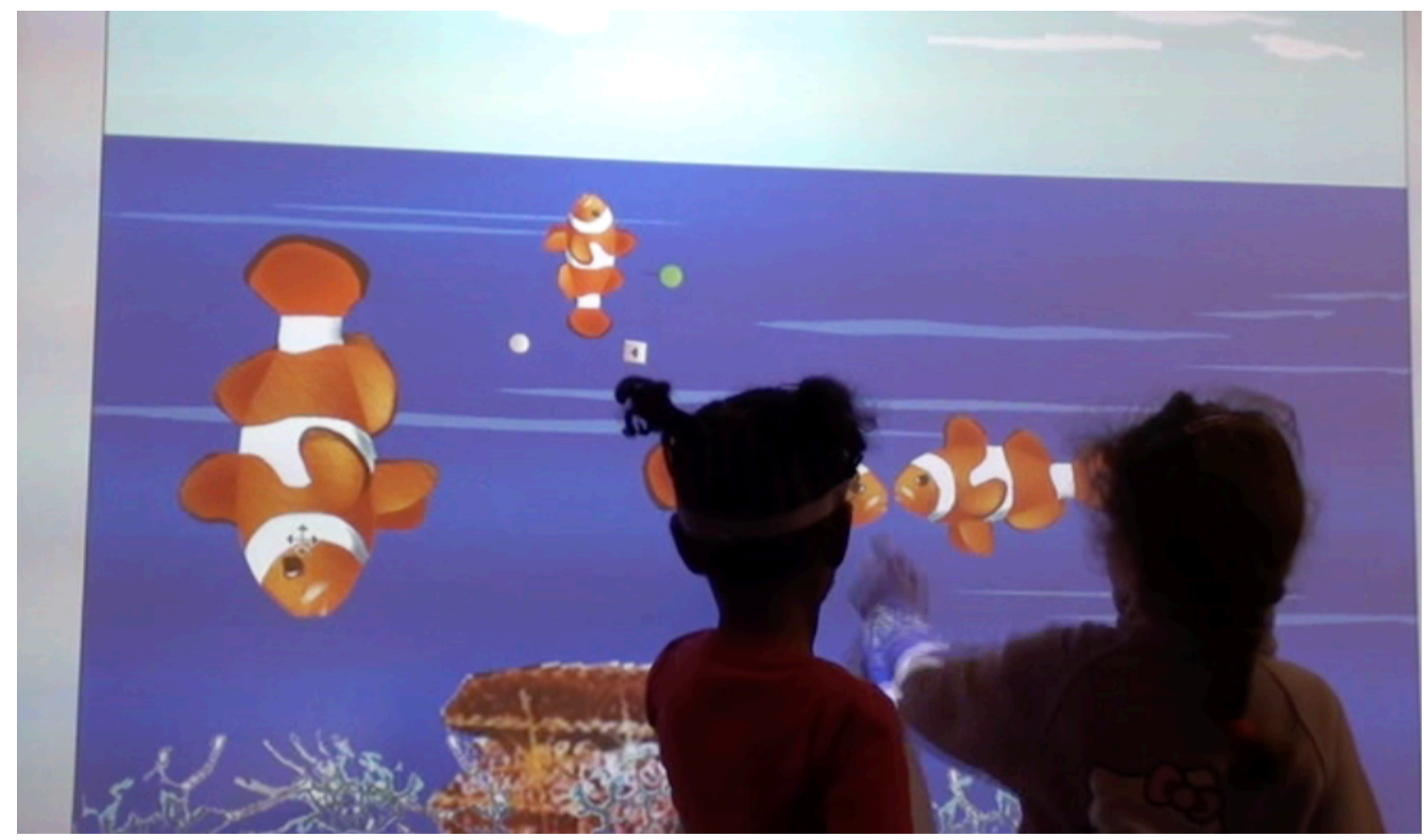

In Figure 2, Ayesha, a three and half-year-old girl, and Amina a four-year-old girl, are seen experiencing the concept of size in terms of big and small as both relative and dependent on the other objects involved in the comparison as well as the concepts of orientation and direction.

\section{Excerpt 6}

1. Teacher: Where is the "biggest" fish! Can we feed the biggest fish in the box; she might be hungry?

2. Ayesha: Yes, here's the biggest, but she isn't hungry!

3. Teacher: Aha, so we should give food to the smallest fish, can you find the smallest fish?

4. Ayesha: Tries to find the fish but it takes a long time, this one (she didn't appear to find the smallest one)

5. Amina: runs towards the board and says, here is the smallest besides the gold chest (pointing to another fish under the box).

6. Ayesha: No way, that is my turn.

7. Teacher: Amina, now it's Ayesha's turn, of course you can wait a moment!

8. Ayesha: Points to a small fish besides the gold chest and says this is the smallest (); and we should feed him.

9. Teacher: Ayesha, why this is the smallest?

10. Ayesha: umm (a bit puzzled...) 


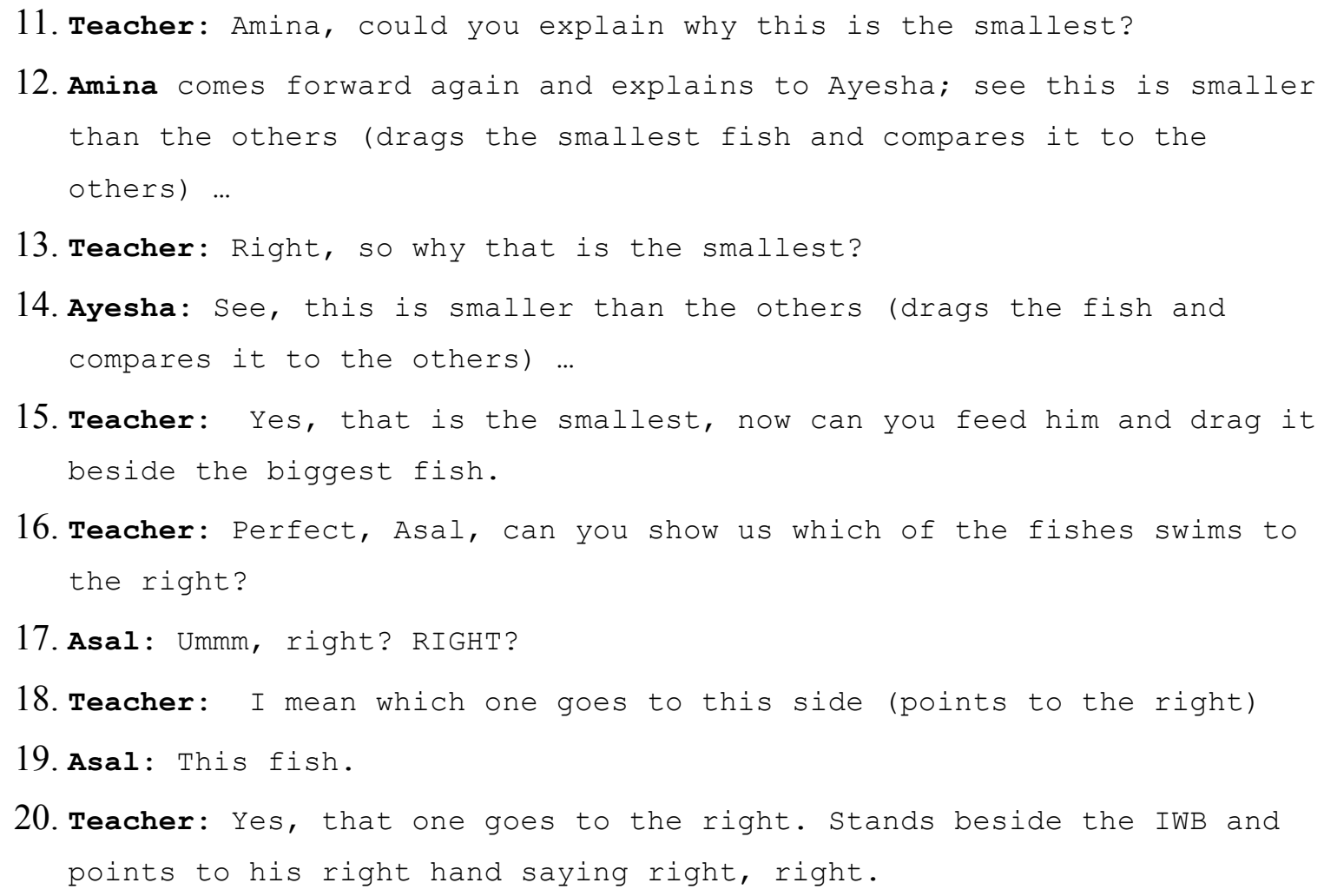

At first, David introduces the concept of small by saying that some of the fish cannot find enough food, but that some are eating too much and getting bigger and bigger. When he invites the children to find the biggest fish he does not indicate what "bigness" is or make any comparisons with other fish on display on the IWB. With an affirmative "Aha" (line 3), the teacher confirms Ayesha's response and reasoning that the biggest fish is not hungry and that they should instead feed the smallest one. In line 4, Ayesha tries to find the smallest fish, but is unable to identify or point to which is the "smallest". At this point, in line 5, Amina draws Ayesha's attention to a fish displayed on the IWB. In line 9 the teacher draws the children's attention to what constitutes smallness by pointing out the different sizes of the fish in order to make the comparison clearer. When given the comparative "smaller", and by Amina's pointing to the IWB, Ayesha manages to identify and point to the "smallest". The teacher repeats the correct answer and then asks Ayesha to place the smallest fish "beside the biggest fish".

In except 7, preschool teacher Mona introduces another way in which the multisensory resources of IWB can be used to enhance young children's reasoning and mathematical learning. Mona and the two young children Noraj and Asil (both four-year-old girls) are working with an application on the IWB for categorizing and classifying objects using the artefact's first letter. As reflected in figure 3, Mona engages the two children in the activity 
displayed on the IWB, in which the children have to identify artefacts beginning with certain letters and drag them to specific boxes.

\section{Figure 3: Classifying objects using the artefact's first letter}

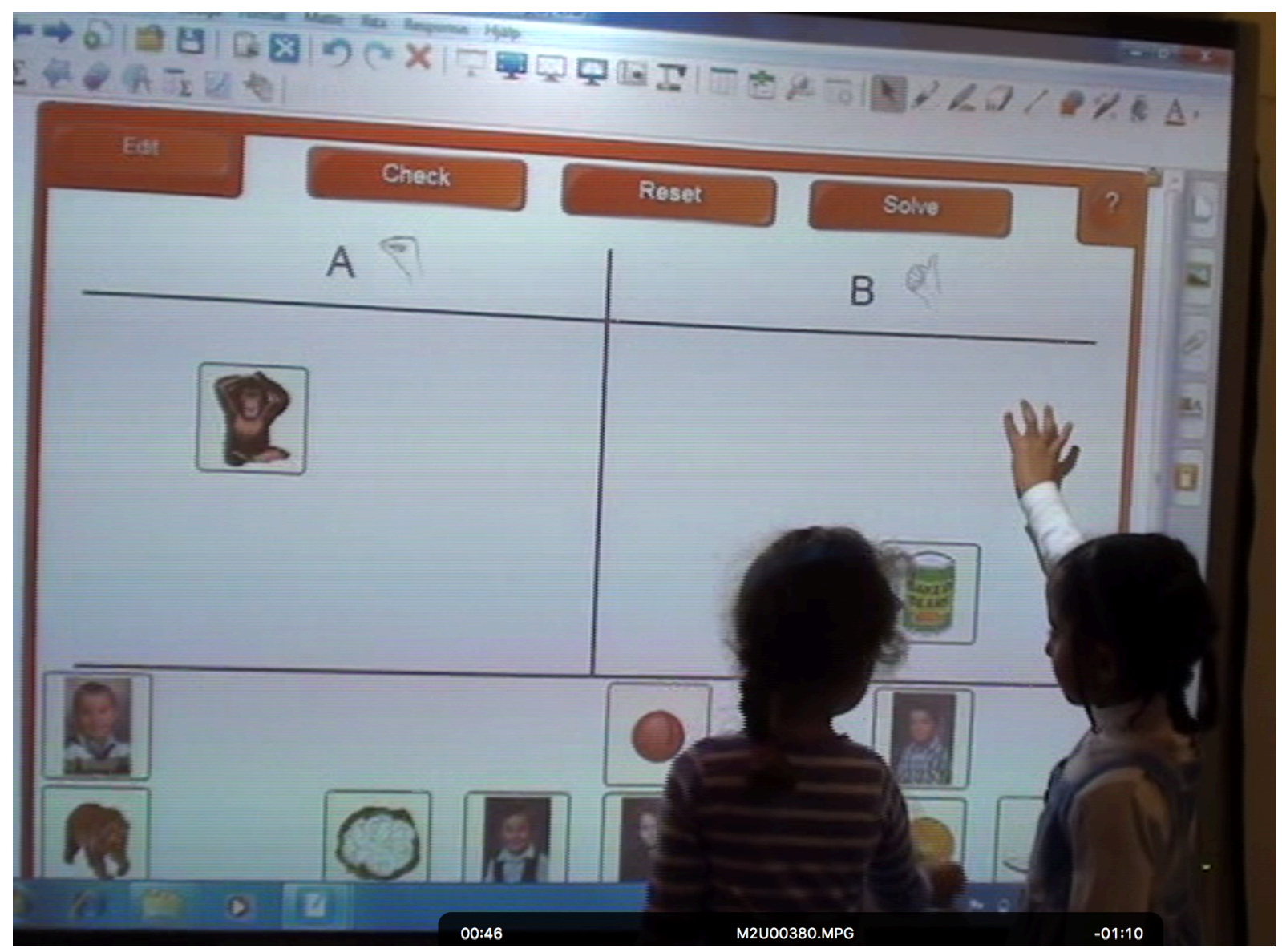

The teacher invites Noraj and Asil to do this by saying: "Noraj, can you put the artefacts beginning with A on the left side in box A, and Asil will you drag the artefacts beginning with B to the right side and put them in box B? You can also explain why you think they should be sorted on the right or the left."

\section{Excerpt 7}

1. Teacher sits on a chair next to the other children. She wonders which of the given artefacts begins with $A$.

2. Noraj: Says "ape" and drags and drops the picture of an ape to box A on the left-hand side.

3. Teacher: Asil! Have a look at the board and see if you can find things / pictures beginning with B.

4. Asil: umm, "bottle" 
5. Teacher: Yes, "bottle", now drag and drop the picture of the "bottle" on the right-hand side in box B. Can you find more things that begin with B?

6. Noraj: Says "apple" and points to the apple. She the drags the picture of the apple to in box A.

7. Asil looks at the board and appears to be thinking.

8. The teacher points to a picture of one her classmates and says "how about this?"

9. Asil: Bertan, points to the picture of her classmate "Bertan".

10. Teacher: Bertan, yes! Can you drag and drop his picture in box B?

11. Asil repeats the name Bertan and makes fun of it by saying "Bertan" "Pertan" (laughs). She says "yes it begins with B". She drags and drops "Bertan's" picture on the right-hand side in box B.

12. Noraj points to the picture of an "ant" and drags and drops it in box A. When Noraj and Asil have sorted all the given objects into the appropriate boxes, the teacher draws the children's attention to how the objects can be sorted differently, depending on whether they are animals, fruit, humans, toys or items of clothing.

13. Asil points to the pictures in box A on the board and says that "ape" and "bear" are animals.

14. Noraj: "buffalo" too......

This excerpt illustrates how Mona engages the children in the activity. The activity entails classifying objects displayed on the IWB beginning with different letters. The children identify the objects, point to them, examine them and talk about them, reasoning why, why not and how the given objects can be placed in the respective boxes. Initially, the teacher invites the two children to place objects in the boxes based on their first letters (line 1). The teacher has already embedded a number of familiar pictures for the children, including those of their classmates whose names begin with A or B. In lines 3 and 5, the teacher encourages Asil to find objects beginning with B. As Asil's Swedish is still poor, the teacher tries to support her by pointing and visualising (see lines 8 and 10). Mona facilitates the process using the multisensory resources offered by the IWB, e.g. by making use of the drag-and-drop function so that the children can physically drag and drop objects into the relevant boxes. She also stimulates the children by asking challenging questions, giving them the necessary information and feedback and engaging them in discussions with each other.

The following excerpt shows how Mats, another preschool teacher, structures an activity with part-whole relationships by numbering and ordering pictures on the IWB. In this excerpt, 
Mats and three young children, Jasmine (a four-year-old girl), Sam (a four-year-old boy) and Nour (a three and half-year-old girl) are working with another application for matching pairs. By putting the pictures in the correct order the children are expected to create a storyline (see Figure 4). In order to turn this into a narrative, the pictures have to be matched with the correct numbers, from one to five. A picture displays a boy climbing onto a stage, one on the panel ready to jump, one jumping into the pool, one in the pool, and one at the side of the pool.

Figure 4. Matching numbers with the correct pictures

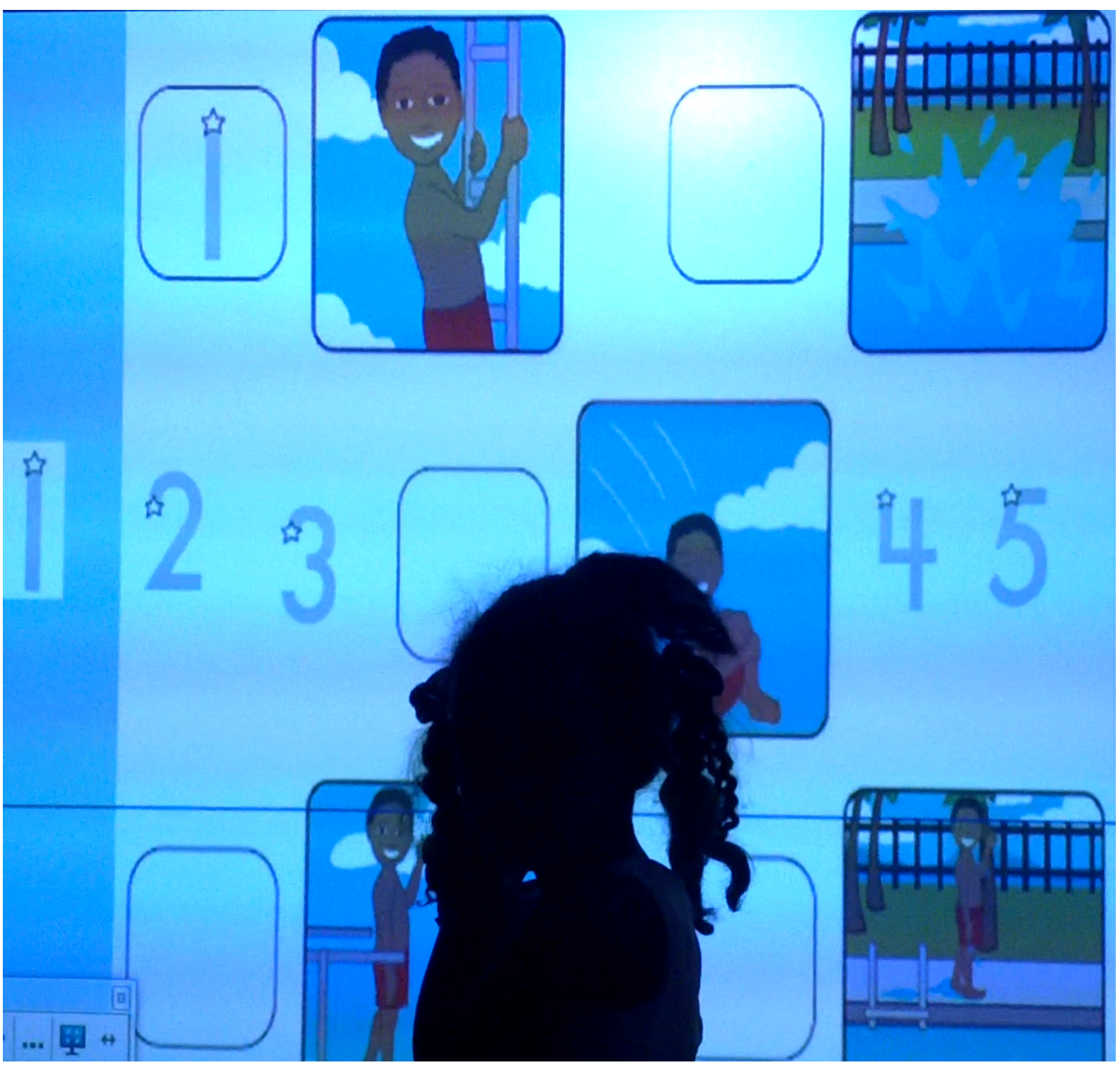

\section{Excerpt 8}

1. Teacher: Can you tell me which picture is number one?

2. Jasmine: I see; she begins to tell the whole story in the correct order. She stands in front of the IWB and points to the picture (the 
boy climbing onto the stage) and says that this is number one. She then points to the picture of the boy on the stage as number two. The boy jumping into the water is number three and the boy in the water is number four. The last picture is that of the boy standing beside the pool.

3. Teacher: Yes, let's put the pictures in the correct order. Sam, can you help me to find which picture is number one?

4. Sam: Sam approaches the table and points to the boy climbing onto the stage.

5. Teacher: Do you mean this picture (points to the picture of a boy climbing onto the stage)?

6. Sam: Yes.

7. Teacher: Great, you can drag number one to the box.

8. Sam: Tries to do this several times but cannot move the number.

9. Teacher: Let's see, we seem to have a problem, but I'll solve it. Mats tries to fix the problem by pressing all the keys on the IWB, but cannot make it work.

10. The children start to chase each other around the room. One of them falls down and begins to cry.

11. Teacher: (after a few minutes) Sorry I couldn't fix it, but I can drag and drop the numbers from the computer.

12. Jasmine: I don't want be here.

13. Teacher: of course, you should help us to match the correct number with the correct picture. Which picture is number 2?

14. Nour: This one, she points to the boy on the stage.

15. Teacher: Yes, we can try that one.

16. Nour: She tries, but cannot move the picture on the IWB.

17. Sam: I want to go to the toilet.

18. Teacher: Ok, you can go.

19. Teacher: I can move the number and put it there from the computer.

20. At the same time Jasmine asks if she can go to the toilet.

21. Nour: I want to go to the toilet too (she leaves the room).

As indicated in line 1, the teacher asks the children to match the numbers with the pictures. One of the children, Jasmine, points to the different pictures in the order in which they appear in the story (line 2). This is followed by the teacher asking another child, Sam, if he can find the first picture (line 3). The teacher confirms Sam's answer by repeating the order he has suggested. The child is unable to drag and drop the picture due to technical problems, which 
the teacher tries to solve by trial and error. The teacher appears to focus on solving the problem and almost forgets the children, especially as the children then begin to chase each other around the room. The activity does not seem to stimulate the children at all - one of the children even says (line 12) that she doesn't want be in the classroom any longer, which the teacher dismisses by saying "Of course, you should help us to match correct number with the correct picture". The teacher tries to continue the activity, albeit unsuccessfully, by asking "Which picture is number 2"?. It is evident that the children are trying to find ways to leave the classroom and in the end excuse themselves by saying that they need go to the toilet. In this activity the children are merely asked to put the pictures in the correct order by dragging and dropping a specific number to an empty box. Moreover, the activity seems to be too easy for the children, especially as one of them tells the entire story in one go at the beginning.

\section{Concluding remarks}

The finding of this study outlines the preschool teachers' reasoning, i.e. the thinking behind the embedding of IWB in the early years' mathematics classroom and the ways in which preschool teachers structure their mathematical activities when using IWB. The findings from the conducted interviews reveal that all the interviewed preschool teachers highlight the importance and significance of embedding technological artefacts, i.e. IWB, in the preschool. Such a positive approach to using IWB in the preschool is mostly linked to enabling the children to engage in problem-solving situations, supporting collaborative learning and mutual negotiation, facilitating goal-oriented mathematics learning and retaining children's interest in learning activities.

However, the intersection between different teachers' technical and pedagogical skills that are reflected in how they use IWB is a thought-provoking issue. As indicated in the results, the way in which one of the preschool teachers, David, embeds IWB in preschool learning practices differs significantly from how the others, particularly Mats, approach it. Taking young children's interests as the point of departure, David develops his own design for activities using the IWB, while the other participating teachers make do with the resources that are available. Goodwin (2008) argues that the successful embedding of IWB in preschool practices depends on how it accommodates young children's interests.

On the other hand, Mats did not manage to sustain the children's interests in the learning activities. By detaching from the context and the interactive nature of the IWB, the preschool 
children were unable to engage in the classroom activities and removed themselves from the learning situation. Although the technological interactivity and multisensory resources of the IWB can motivate and challenge young children, it is the pedagogical interactivities, i.e. interaction between preschool teacher and children designed to bring about learning with the IWB as mediator (Smith, Higgins, Wall, \& Miller, 2005), that are more important when it comes to stimulating and engaging children in mathematical learning activities.

The mere fact of having or using IWB does not create a dynamic and rewarding learning environment in the preschool. Preschool teachers' pedagogical and technological knowledge shapes the ways in which they embed IWB in preschool pedagogical practices. Similarly, using IWB does not automatically turn preschool teachers into excellent teachers. In other words, IWB does not necessarily impact on the teaching or its quality, although it can be very effective in the hands of skilled teachers (Armstrong et al., 2005). Preschool teachers' use of ICT may largely depend on their existing values, technical expertise and pedagogical experience. In order to embed IWB in preschools' educational practices, preschool teachers' technological knowledge needs to be enhanced, which involves a complex coupling between technical knowledge and pedagogical expertise (see Koehler \& Mishra, 2009; Mishra \& Koehler, 2006). Interestingly, out of those observed, David is the only preschool teacher to have attended three professional development courses on the use of IWB. The other participants partly developed their IWB competences by trial and error (using different online resources and application manuals) and partly by talking to colleagues.

The current study's findings support a number of the claims made about IWB (see Clemens, Moore, \& Nelson, 2001; Kjällander, 2014; Miller \& Glover, 2010; Morgan, 2010). While the interactivity features and multisensory resources of IWB can motivate and challenge young children, it is the preschool teacher's pedagogical approach and the roles that he or she ascribe to the technology (Smith., Hardman, \& Higgins, 2006) that play a key role in engaging preschool children in mathematical learning. Thus, it can be suggested that in addition to enhancing preschool teachers' pedagogical knowledge, it is also necessary to enhance their technological knowledge of how to use IWB for learning purposes.

A known argument for the integration of digital technological artefacts in the preschool is that such artefacts can be used to promote and enhance children's competences. However, the question remains as to how IWB can develop competences that are essential for their development? Numerous programmes and design applications are available for IWB that children can use to build three-dimensional structures. Would using such applications on IWB 
help preschool children to learn maths? It is argued that children's learning and creativity are stimulated by giving them different experiences, e.g. non-digital and digital. Based on the findings of the study, it is possible to argue that teachers could use IWB to develop a variety of learning activities that engage and motivate children to learn based on their own interests.

In order to accommodate children's needs, it can be argued that instead of using ready-made applications and educational resources, teachers should be encouraged to develop their own teaching resources and applications on IWB. Preschool teachers' reflections on such didactical questions, in terms of why, what, how and so on, may lead to a critical analysis of the extent to which IWB could or should contribute to children's learning.

\section{References}

Armstrong, V., Barnes, S., Sutherland, R., Curran, S., Mills, S., \& Thompson, I. (2005). Collaborative research methodology for investigating teaching and learning: The use of interactive whiteboard technology. Educational Review, 57(4), 457-469. doi:10.1080/00131910500279551

Björklund, C. (2010). Broadening the horizon: Toddlers' strategies for learning mathematics. International Journal of Early Years Education, 18(1), 71-84.

Björklund, C. (2012). What counts when working with mathematics in a toddler-group? Early Years, 32(2), 215-228.

Clemens, A., Moore, T., \& Nelson, B. (2001). Math intervention 'SMART' project (student mathematical analysis and reasoning with technology). Retrieved from http:// www.smarterkids.org/research/paper10.asp

Clements, D. H., Sarama, J., \& DiBiase, A. M. (2003). Engaging young children in mathematics: Findings of the 2000 National Conference on Standards for Preschool and Kindergarten Mahwah, NJ: Lawrence Erlbaum Associates.

Creswell, J. W. (2012). Educational research: Planning, conducting, and evaluating quantitative and qualitative research (4th ed.). Boston: Pearson.

Divaharan, S., \& Koh, J. H. L. (2010). Learning as students to become better teachers: Preservice teachers' IWB learning experience. In M. Thomas \& A. Jones (Eds.), Interactive whiteboards: An Australasian perspective. (Vol. 26, pp. 553-570). Australasian: Educational Technology.

Doverborg, E., \& Emanuelsson, G. (2006). Små barns matematik: Erfarenheter från ett pilotprojekt med barn 1-5 år och deras lärare. Göteborg: Göteborgs universitet och Nationalt centrum för matematik.

English, L. D. (2004). Mathematical and Analogical Reasoning in Early Childhood. In L. D. English (Ed.), Mathematical and analogical reasoning of young learners (pp. 1-23). Mahwah, New Jersey: Lawrence Erlbaum Associates.

Glaubke, C. R. (2007). The Effects of interactive media on preschoolers' learning: A review of the research and recommendations for the future. Oakland, CA: Children Now.

Goodwin, K. (2008). The impact of interactive multimedia on kindergarten students' representations of fractions. Educational Research, 18(2), 103-117. 
Kervin, L. K., Verenikina, I., Wrona, K., \& Jones, P. T. (2010). Interactive whiteboards: interactivity, activity and literacy teaching. Paper presented at the Proceedings of World Conference on Educational Multimedia, Hypermedia and Telecommunications, VA, USA.

Kjällander, S. (2014). Appknapp: Peka, lek \& lär $i$ förskolan. Retrieved from http://appknapp.se/?p=1905

Koehler, M. J., \& Mishra, P. (2009). What is technological pedagogical content knowledge? Contemporary Issues in Technology and Teacher Education, 9(1), 60-70.

Maher, D. (2011). Using the multimodal affordances of the interactive whiteboard to support students' understanding of texts. Learning, Media and Technology, 36(3), 235-250.

Masoumi, D. (2015). Preschool Teachers use of ICTs: Towards a typology of practice. Contemporary Issues in Early Childhood (CIEC), 16(1), 5-17.

McCarrick, K., \& Li, X. (2007). Buried treasure: The impact of computer use on young children's social, cognitive, language development and motivation. AACE, 15(1), 7395.

Mercer, N., Hennessy, S., \& Warwick, P. (2010). Using interactive whiteboards to orchestrate classroom dialogue. Technology, Pedagogy and Education, 19(2), 195-209.

Miller, D., \& Glover, D. (2010). Presentation or mediation: Is there a need for 'interactive whiteboard technology-proficient' teachers in secondary mathematics? Technology, Pedagogy and Education, 19(2), 253-259. doi:10.1080/1475939x.2010.491236

Mishra, P., \& Koehler, J. M. (2006). Technological pedagogical content knowledge: A framework for teacher knowledge. Teachers Collage Record, 108(8), 1017 - 1054.

Morgan, H. (2010). Teaching with the interactive whiteboard: An engaging way to provide instruction. Focus on Elementary, 22(3), 3-7.

Muir, T., Callingham, R., \& Beswick, K. (2016). Using the IWB in an Early Years Mathematics Classroom: An Application of the TPACK Framework. Journal of Digital Learning in Teacher Education, 32(2), 63-72. doi:10.1080/21532974.2016.1138913

Penuel, W. R., S, Pasnik, L., Bates, E., Townsend, L. P., \& Gallagher, C. (2009). Preschool teachers can use a media-rich curriculum to prepare low-income children for school success: Results of a randomized controlled trial. New York: Education development.

Plowman, L., \& Stephen, C. (2003). A 'benign addition'? Research on ICT and pre-school children. Journal of Computer Assisted Learning, 19(2), 149-164.

Pramling Samuelsson, I., \& Sheridan, S. (2007). Lärandets grogrund - Perspektiv och förhållningssätt i förskolans läroplan. Stockholm: Studentlitteratur.

Sarama, J. (2004). Technology in early childhood mathematics: Building blocks as an innovative technology based curriculum. In H. Douglas, D. H. Clements, \& J. Sarama (Eds.), Engaging young children in mathematics: Standards for early childhood education. Mahwah, NJ: Lawrence Erlbaum.

Shadish, W. R., Cook, T. D., \& Campbell, D. T. (2002). Experimental and quasiexperimental designs for generalized causal inference. Boston: Houghton Mifflin.

Smith, A., Gentry, A. R., \& Blake, S. (2012). Mathematics Learning through the Use of Technology. In S. Blake, D. Winsor, \& L. Allen (Eds.), Technology and young children: Bridging the communication-generation gap (pp. 199-221). Hershey, PA: Information Science Reference. 
Smith, H. J., Higgins, S., Wall, K., \& Miller, J. (2005). Interactive whiteboards: Boon or bandwagon? A critical review of the literature. Computer Assisted Learning, 21, 91101.

Smith., F., Hardman, F., \& Higgins, S. (2006). The impact of interactive whiteboards on teacher-pupil interaction in the National Literacy and Numeracy Strategies. British Educational Research Journal, 32(3), 443 - 457.

SOU. (2014:13). En digital agenda i människans tjänst - en ljusnande framtid kan bli vår. Retrieved from Stockholm:

The Swedish National Agency for Education. (2011). Curriculum for the Preschool Lpfö 98 Revised 2010. Stockholm: Skolverket.

The Swedish National Agency for Education. (2013). It-användning och it-kompetens $i$ skolan. Stockholm: Skolverket.

Watson, A., \& De Geest, E. (2005). Principled teaching for deep progress: Improving mathematicallearning beyond methods and materials. Educational Studies in Mathematics, 52(2), 209-234. 